\title{
AN IOT BASED APPROACH FOR MONITORING SOLAR POWER CONSUMPTION WITH ADAFRUIT CLOUD
}

\author{
Mubashir Ali \\ Department of Software Engineering, Lahore Garrison University, Lahore, Pakistan \\ Mahnoor Khalid Paracha \\ Department of Computer Science, Bahauddin Zakariya University, Multan, Pakistan
}

\begin{abstract}
Internet of things is an emerging technology that efficiently and effectively improving our daily life activities. It reducing the cost of living by automating the manual processes. It integrates physical objects and devices via internet for synchronized communication. Currently the cost of electricity is reaching the sky so we need some sources that can produce electricity naturally without any cost. Here, solar panels and solar plants take place for producing electricity in natural manner with sun light. Photo voltaic cells are used in these systems that converts the sun light into electricity. Mostly the solar systems are configured in rural or agricultural areas where electricity mediums are still not available. These systems are manually operated by humans. So there is need of efficient approach which automatically control and monitor the current, voltage and other parameters of solar systems and provides real time statistics to users. This research paper proposes an IOT based approach for solar power consumption and monitoring that allow the users to monitor or control a solar plant their mobiles. Majorly, solar plants are built in the locations where people cannot reach on daily basis so this approach allows the people to virtually control their systems from faraway places.
\end{abstract}

Keywords - Solar System, Power Monitoring, Consumption Monitoring, Internet of Things, Cloud Computing, Arduino

\section{INTRODUCTION}

Internet of Things (IOT) is a futuristic technology which enables a machine to be controlled or sensed remotely by help of a server known as cloud server [1]. Now a days, it is used in every walk of life and automating the daily life activities, enabling exchange of data between human to machine and machine to human, monitoring or controlling of physical devices remotely from faraway places [2]. It has broader impact on digital and physical devices, machines, objects, humans, animals etc. [3]. People are able to access all the functionalities of their machines, robots or other devices which are based on IOT system. IOT connecting a large variety of things with each other like smart cities, smart vehicles, monitoring systems, smart road lights, shopping system, automated homes, environmental sensors and etc. [4] IOT enabling machines to act on its own and these machines will not be dependent on humans any more for performing their functions [5]. Today electricity is running the world and without electricity we cannot do anything. Electricity is used in every part of our daily life like in lighting of houses, refrigerators, heaters, coolers, transport etc. [6]. As time passes electricity consumption increases so the electricity production should also be increased. But in our country and other developing countries, electricity is not produced in large quantity to meet its requirements. The price of electricity is also increasing which most of the people cannot afford. To meet this problem, we need a very efficient system that can produce electricity with natural resources. Solar power plants are developed to overcome these issues. But proper production and consumption of electricity is another issue in solar plants. There is also need efficient techniques to measure, manage and control the solar panels. These solar plants become a source of light in areas where there is no electric power run commercially [7]. This resource of energy is one of best energy resource which has no harm on humans or other living creatures and also not to the environment [8]. Photo voltaic cells are used in these solar power plants, when the sun light falls on it these cells convert this sun light directly into electricity. Batteries are connected with these solar panels which store electricity and then supply this electric power in homes, factories, schools [9]. Some of the solar plants are built nearby which are easily accessible but some of these plants are built in locations where people cannot travel in routine to check plant activities [10]. So, this research paper purposes a very efficient IOT based solar power consumption and monitoring approach which enables the users to check the activities of these solar plants by sitting in faraway places. Solar plants have to be checked regularly that it is working properly or not. In this research, a prototype is developed to implement the proposed technique to validate the results that the system provides with real time monitoring over solar plants. All the functioning, usage, energy, heat etc. is shown via mobile application. Arduino is used as a main board of system that controls the charging and the usage of the electricity in the whole system and then upload these parameters to the cloud [11]. We used Adafruit cloud services for storing and communicating the real time statistics [12]. 
IOT welcoming new emerging technical platforms on ground [13]. The prototype warned the user in case of battery full and cannot store more electricity [14], So the user will be able to control the system accordingly.

Rest of the paper is categorized in four sections. Section two review the literature to highlight the relevant work and considerable parameters of solar systems. In section three, system design is elaborated with the help of block diagram and working flow of system. Furthermore, this section illustrates the experimental setup. Section four discusses the experimental results with the help of graphs. Section five, finally concludes the paper and shows the future directions.

\section{LITERATURE REVIEW}

The conventional sources of electricity are depleting so there is need of some non-conventional resources which can be used for lifetime. One of the source is solar power system. This system stores and supply electricity by converting sunlight into electricity. When there is no sunlight to convert sun rays into electric power then the batteries supply already stored electricity. These IOT based PV systems are the next generation system which will improve the monitoring of solar systems [2]. Another low cost IOT based PV system is proposed by [4].. They used GPRS module and a low-cost microcontroller which will receive every information from the PV system. IOT is widely spread in world of electronics. This system measures the temperature and current of PV system. The data of system is accessed through a website. One of the non-conventional electricity resource is the solar power panel and due to the huge decrease in the cost of modern technologies, these solar power systems are very cheap and accessible now [12]. But these systems need monitoring regularly so peoples track and control effectively. Data logger and monitoring methods are very important for the better working of a solar systems. These methods enable us to get all the information of the system about malfunctioning before any greater damages. Another paper proposed a IOT based solar power system that use raspberry pi for component integration [3]. This system also provides constant statistics via website. The data logger records about humidity, temperature, voltage and current. Kishore et all proposed another cloud based solar system monitoring technique which transfers constant records over cloud after a specific time [15]. The analysis of current status about solar system becomes easy by continuous tracking the power plant. The benefit of analysis is that it is helping for finding or detecting the possible fault in system and kept on eye on output from a large distance. Rakesh et all proposed another ecofriendly solar system. Power generated are monitored in real time and update in server [7]. As world faces shortage of renewable resources so every country moves towards the solar systems and scientist put their efforts to make them efficient. Abilash et all discusses the working of photo voltaic cell in detail to present the solar system to meet the ever growing technological advancements [16]. Dust on the solar panels also effect the performance of the solar panel in utilization of energy. This paper proposes a system which gives the solution and method for the monitoring of the solar panel's dust accumulation [1]. This system monitors the dust formed on the solar panels, blocking the radiations from reaching the panels. This system contains LDR sensor with NodeMCU for dust checking. Solar power plants should be monitored regularly for best output. The system in this proposed research paper uses AT mega controller to control the parameters. This system continuously monitors the performance of solar plant and upload parameters over the cloud [17]. Another system is present by [10] and in this system different parameters of the solar panels are monitored i.e. intensity, current, voltage, temperature and power. They used Arduino UNO controller with LDR censors to monitor the light intensity. ACS712 and LM35 is used her to measure the load current. After this all the parameters are displayed on LCD.

\section{System Design And ExPerimental SetuP}

In our proposed technique, all the energy produced by the solar panels is continuously monitored. The sensors attached to the system sense the conditions and Arduino analyze the data received from these sensors about parameters. It has a Wi-Fi module which help in connecting the mobile [18]. All these parameters are uploaded to the cloud and the user can have access of these real time parameters any time [19].

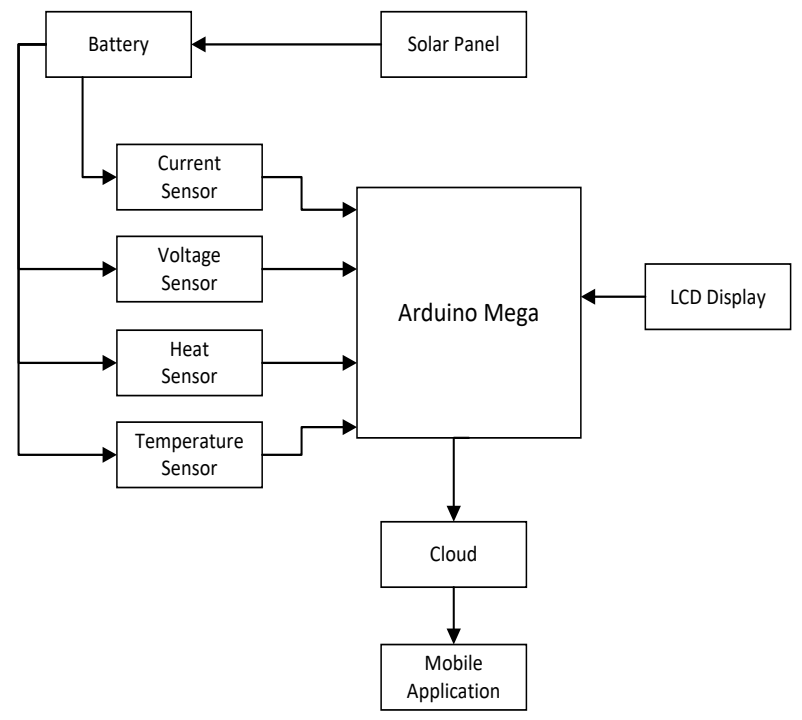

Fig. 1. Block Diagram

Figure 1 represents a block diagram of proposed approach in which Arduino Mega 2560 microcontroller chip integrates with all essential sensors, components and analyzing statistics. There are 4 sensors attached to the Arduino which sense the different factors that have an effect on the whole system. These sensors are attached to the battery and the battery is attached to the solar panel. Arduino further more connects to the ESP8266 with an LCD display. 
The following figure 2 shows the process of the whole system explained through a flow diagram. In start, Arduino is initiated, then a connection is established with the internet. If the connection is established successfully than the system proceeds and if connection fails, the system sends an error message. After successful connection with internet, an IP address is generated, then the input is taken from the solar panel and the sensors attached to the panel access the input and pass them to the Arduino microcontroller [20]. Arduino process the initial data and transfer over cloud. These parameters are displayed on the LCD display and also uploaded to the cloud and user can have access of this data via mobile application.

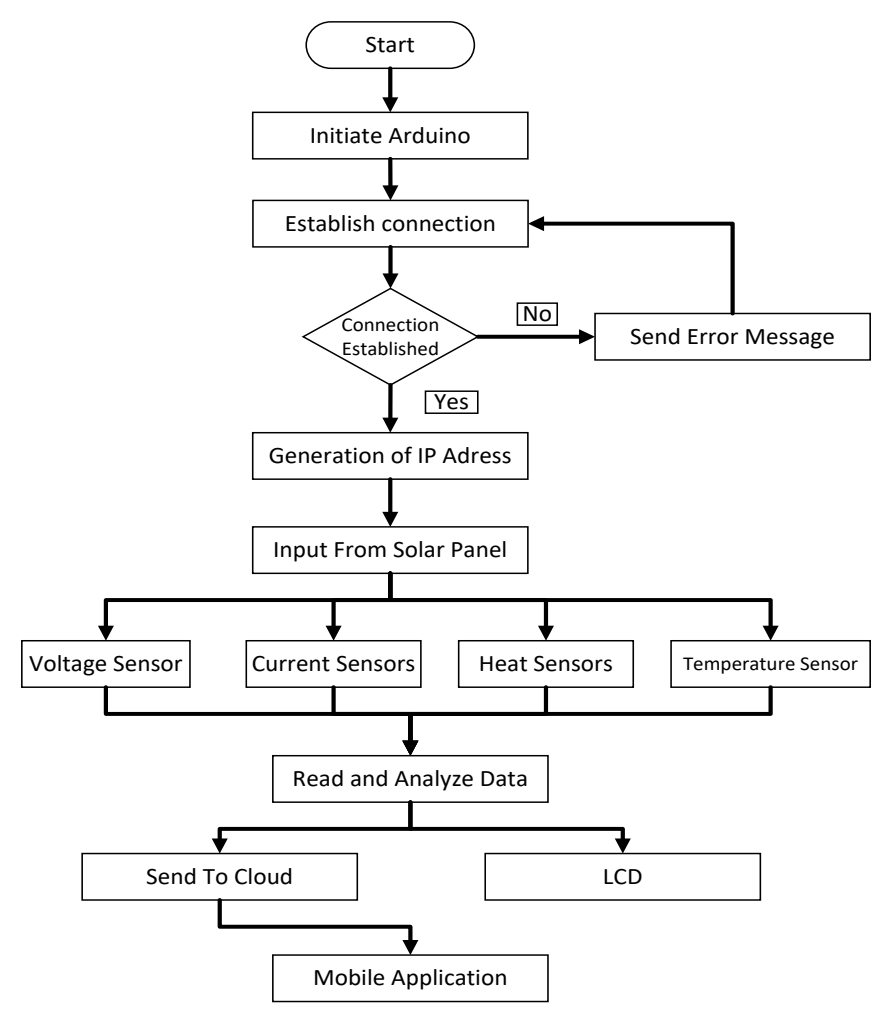

Fig. 2. Process Chart of Proposed Approach

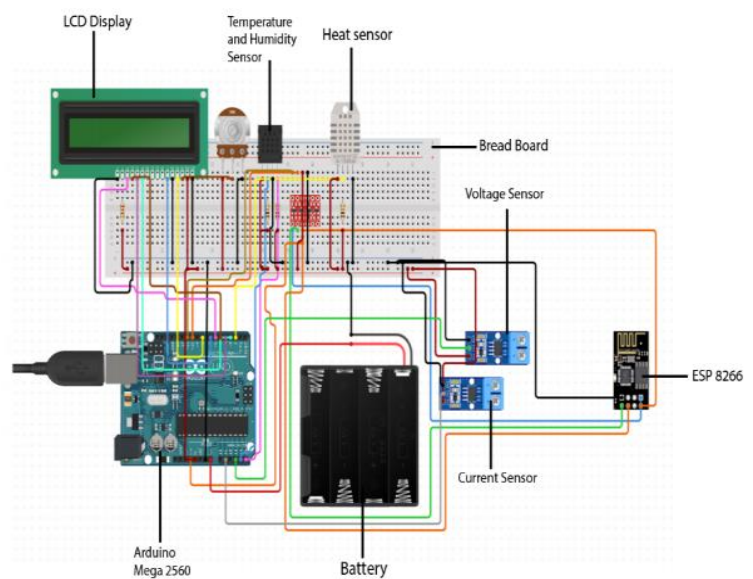

Fig. 3. Circuit Diagram

Figure 3 shows the circuit diagram of proposed approach that how the system will be integrated. There are four sensors voltage, current, heat and temperature and humidity sensor which are connected with Arduino as well as bread board. There is a battery attached with bread board and Arduino. The LCD display and ESP8266 is connected to the board and Arduino.

\section{Hardware Components}

Following components are used to build the prototype of underlying system.

\section{A. Arduino Mega 2560}

It is an advanced board for integrating different sensors and devices for automation [21]. It has a total 54 pins for the input/output in digital form, 16 analog inputs, a $16 \mathrm{MHz}$ crystal oscillator, 4 UARTs, a USB connection, an ICSP header, a power jack, and a reset button. It has everything needed to support the microcontroller, just connect it to the computer with a USB cable or power it with an AC-to-DC adapter or a battery to get started.

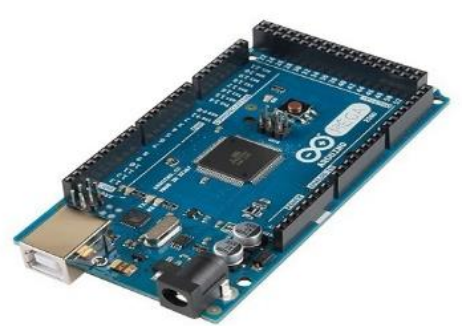

Fig. 4. Arduino Mega 2560

B. Solar Panel

It consists of photo voltaic cells. When the sun light or radiations fall on them these PV cells convert these radiations in to electrical energy. These PV modules uses photons from the sun light and generate electrical energy. Which is then stored in batteries and supplies to homes, offices etc. The suns radiation has variations to handle these variations we use specific sensors [22].

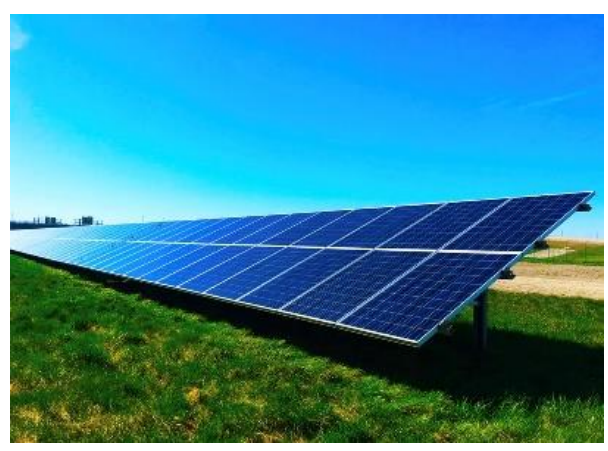


Fig. 5. Solar Panels

\section{Battery}

It is device which contains one or more electro chemical cells. It has two terminals cathode and anode with are used for the connection of battery with any device [23]. The electrical energy produces by the solar panels is stored in these batteries which helps in providing energy to appliances.

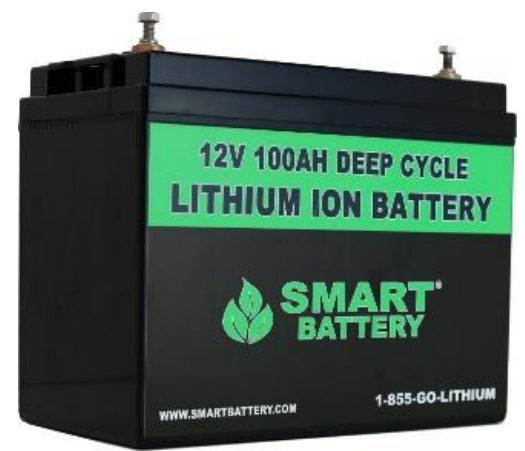

Fig. 6. Battery

\section{LCD Display}

It is used for the display of the parameters which are fetched by the Arduino Mega 2560 from the sensors.

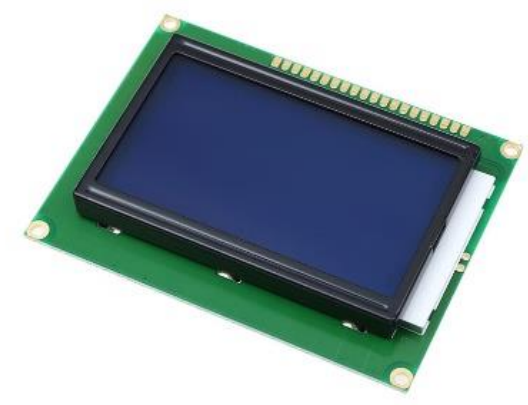

Fig. 7. LCD display

\section{E. Current Sensor ACS712}

It is device which detects the electrical current passing through any material and then generate signals which are same to the electrical current. This signal can be an analog signal or a digital signal. The current signals are passed through ammeter for measuring current.

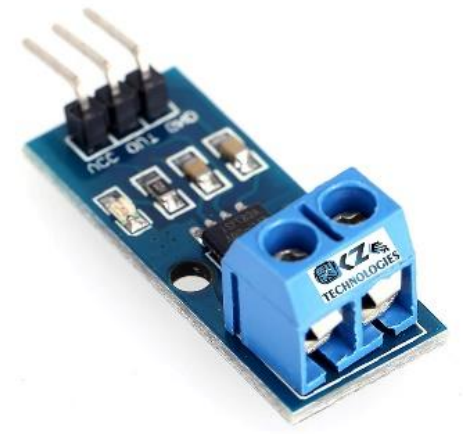

Fig. 8. Current Sensor ASC712

\section{F. Voltage Sensor}

This device converts voltage in a circuit in to the physical signal same as the voltage. Then this physical signal helps in measuring the voltage difference between two points.

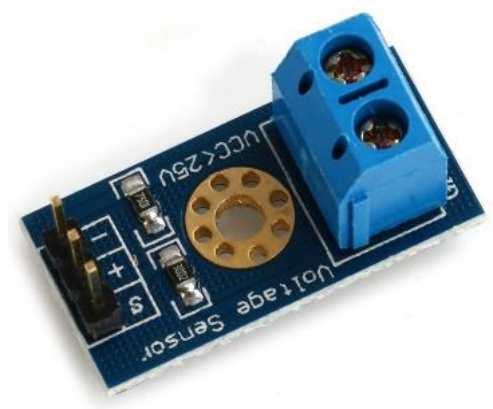

Fig. 9. Voltage Sensor

\section{G. Heat Sensor}

It is a device which is used to analyze or sense the heating of a system when it is running. It helps us to cools down the system and prevent the excess of heating.

H. Temperature and Humidity Sensor RHT03

It is the sensor which is used to sense the temperature of the system while it is running [25]. It helps us to know the system temperature and if the temperature exceeds than we can control it. It also checks the humidity in the atmosphere to check the radiations falling on it.

\section{Adafruit Cloud}

Adafruit is a cloud server that is specially developed for internet of things projects. It provides various statistical tools on single clicks. The data of parameters are moved over cloud. Multiple post operations are performed on data over cloud and mobile application also access data from cloud. 


\section{International Journal of Engineering Applied Sciences and Technology, 2020}

Vol. 4, Issue 9, ISSN No. 2455-2143, Pages 335-341

Published Online January 2020 in IJEAST (http://www.ijeast.com)

\section{EXPERIMETNAL RESULTS}

The results of our system can be shown directly on the LCD display attached to the whole system and it also available through mobile device. Specific mobile application is developed that fetches the data from the cloud and display the real time results to user.

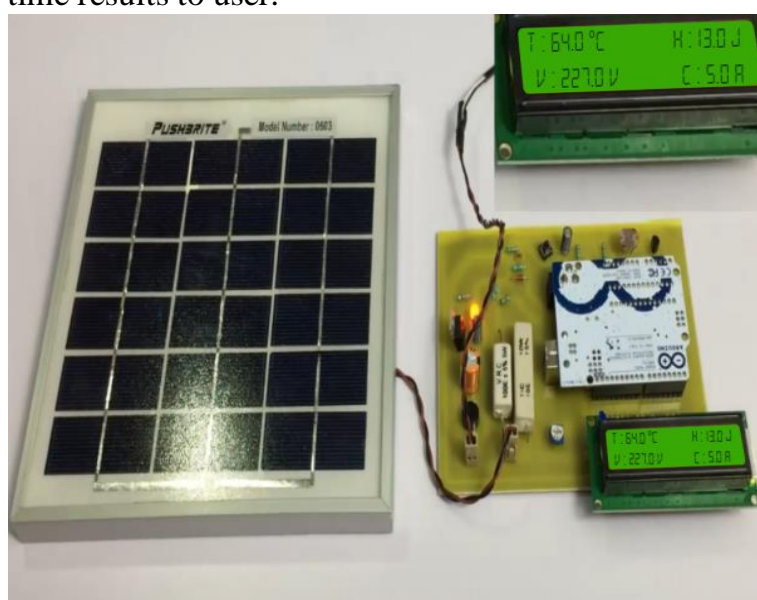

Fig. 10. Proposed Approach Prototype with Results

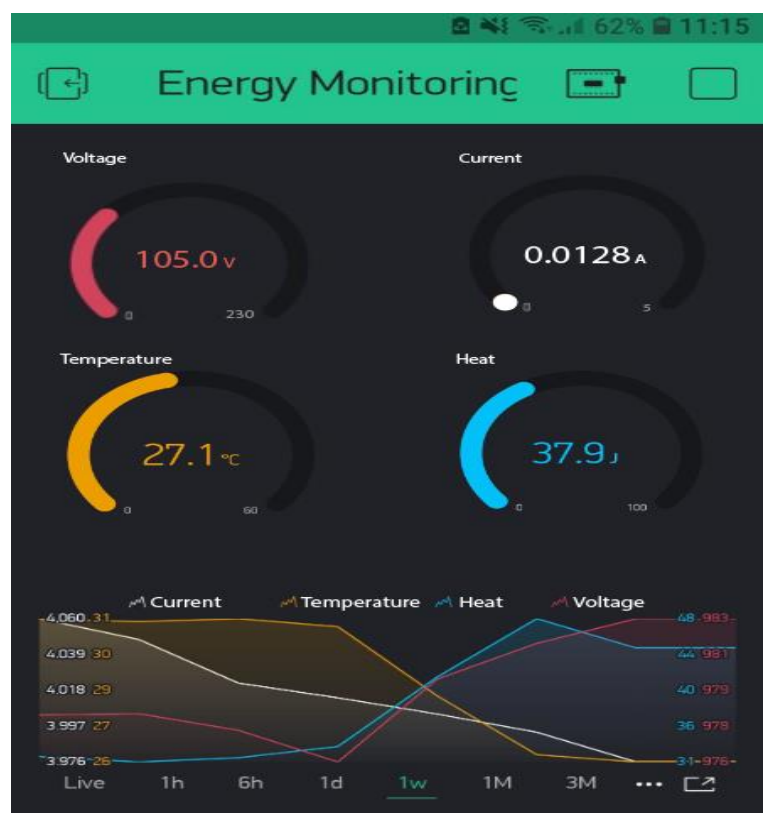

Fig. 11. Real Time Results over Mobile Application

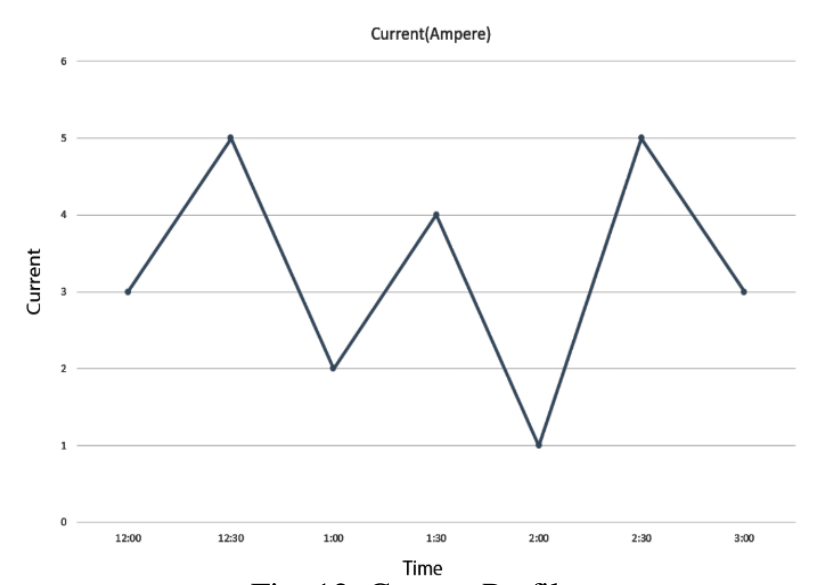

Fig. 12. Current Profile

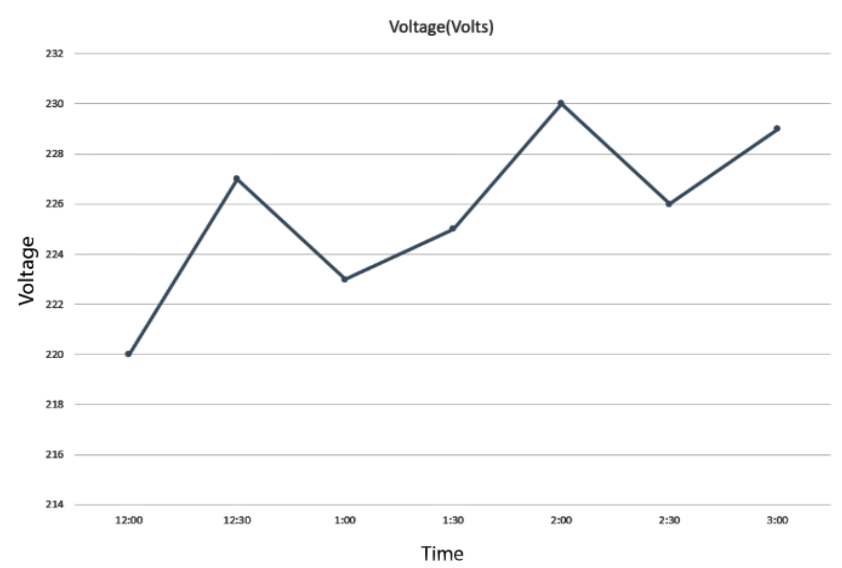

Fig. 13. Voltage Profile

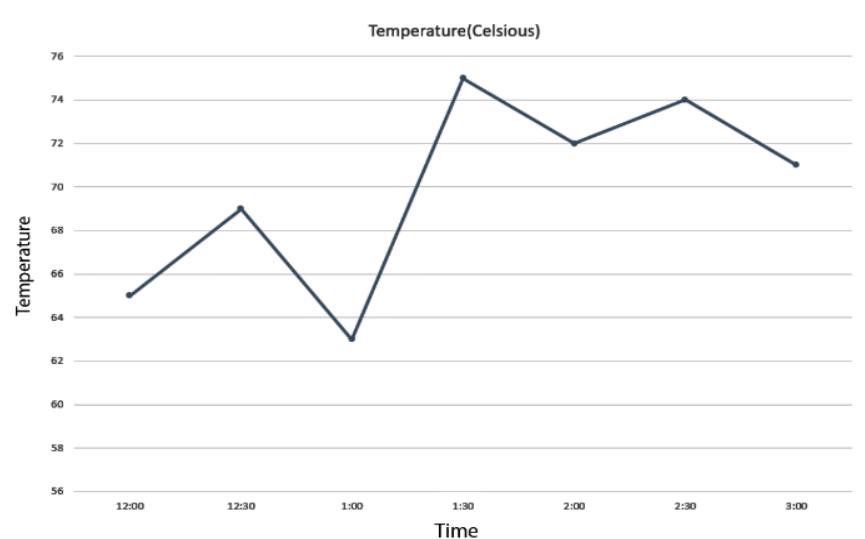

Fig. 13. Temperature Profile 


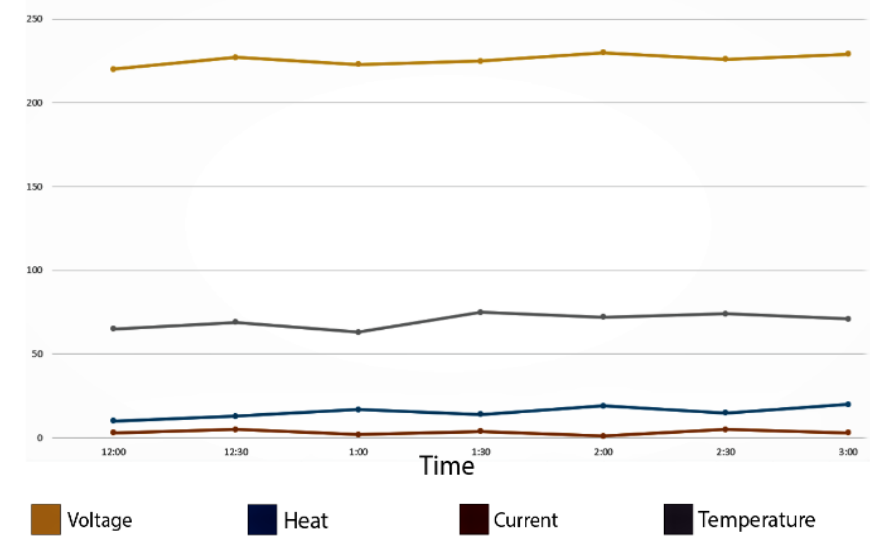

Fig. 15. Comparative profile of Current, Voltage and Temperature

In this figure 16 the mobile display of all parameters is shown which were uploaded to the cloud and the user can have access of it anywhere.

\section{CONCLUSION}

The need of electricity is rising day by day and traditional sources of energy are not producing enough to meet this graph. This exponential need also effects on electricity cost and human lives. Internet of things revolutionizing human lives in every field of life. Solar panel are not traditional source of electricity that may fulfil the need of energy. In this paper, an IOT based approach for monitoring the solar power consumption is presented and a prototype is developed to simulate the results. The underlying approach records the solar panel perimeters like current, voltage and temperate via sensors and transfer over cloud using Arduino. Results are displayed via onboard screen as well as mobile application. Users will be able to track, monitor and control their panel virtually to maximize the electricity. In future, we will implement reinforcement learning algorithm to predict the future usage and electricity production of solar panels.

\section{CONFLICT OF INTEREST}

On behalf of all authors, the corresponding author states that there is no conflict of interest.

\section{ACKNOWLEDGEMENT}

We would like to thank the journal editor, area editor and anonymous reviewers for their valuable comments and suggestions to help and improve our research paper.

\section{REFERENCE}

1. L.R. Lokesh Babu R, Rambabu D, Rajesh Naidu A, D. Prasad R, Gopi Krishna P. Solar Power Monitoring System using IOT. J. Eng. Technol. 2018;7:526.

2. Singh SR. Engineering IOT in Education (IoTE): An Overview. J. Innov. Res. Comput. Commun. [Internet] 2017;11324-8. Available from: www.ijircce.com 3. Tellawar MP. Smart Solar Photovoltaic cell Remote
Monitoring System based on IOT. 2019;8:235-40.

4. Suresh, Ankit K, Gawre. Solar photovoltaic cell remote monitoring system based on IOT. Conf. Recent Innov. Signal Process. Embed. Syst. 2018;2018Janua:619-23.

5. Shanthi T, Anushree S V, Prabha SU, Rajalakshmi D. DAC to monitor solar powered home appliances and usage control using bluetooth enabled mobile application and IoT. Proc. 2017 Int. Conf. Innov. Information, Embed. Commun. Syst. ICIIECS 2017 2018;2018-Janua:1-4.

6. Ms. Apurva L MMN. IoT based Solar Monitoring System. IEEE 5th World Forum Internet Things, WFIoT 2019 - Conf. Proc. 2016;3:1-18.

7. Padma S, Ilavarasi PU. Monitoring of Solar Energy using IOT. J. Eng. Technol. 2017;4:596-601.

8. Chieochan O, Saokaew A, Boonchieng E. Internet of things (IOT) for smart solar energy: A case study of the smart farm at Maejo University. 2017 Int. Conf. Control. Autom. Inf. Sci. ICCAIS 2017 2017;2017Janua:262-7.

9. M, Tapaskar S, Vijayalashmi, Patil R. Solar power monitoring system based on IOT. J.Sci.Res Indian [Internet] 15:149-55. Available from: https://www.ijsr.in/upload/1455558654Chapter_26.pd f\%0Ahttps://www.mendeley.com/catalogue/solarenergy-monitoring-system-using-iot/

10. Spanias AS. Solar energy management as an Internet of Things (IoT) application. 2017 8th Int. Conf. Information, Intell. Syst. Appl. IISA 2017 2018;2018Janua: $1-4$.

11. Patil A, Deokar SA, Banderkar A. GRID TIE Solar Power Plant Data Acquisition System using Internet of Things. 2018 Int. Conf. Information, Commun. Eng. Technol. ICICET 2018 2018;1-4.

12. Subhasri G. A Study of IoT based Solar Panel Tracking System. Innov. Syst. Technol. 2018;11:53745.

13. Prasanna JL, Lavanya D, Kumar TA. Condition monitoring of a virtual solar system using IoT. Proc. 2nd Int. Conf. Commun. Electron. Syst. ICCES 2017 2018;2018-Janua:286-90.

14. Adhya S, Saha D, Das A, Jana J, Saha H. An IoT based smart solar photovoltaic remote monitoring and control unit. 2016 2nd Int. Conf. Control. Instrumentation, Energy Commun. CIEC 2016 2016;432-6.

15. Kandimalla J, Kishore | D Ravi. 6 International Journal for Modern Trends in Science and Technology. J. Mod. Trends Sci. Technol. 2017;03:16-21.

16. B Derin SVBAGASK. IoT based Solar Monitoring System. SSRN Electron. J. 2016;3:1-18.

17. Ahrary A, Inada M, Yamashita Y. Solar power monitoring system "SunMieru." Innov. Syst. Technol. 
2018;73:216-24.

18. Deshmukh NS, Bhuyar DL. A Smart Solar Photovoltaic Remote Monitoring and Controlling. Proc. 2nd Int. Conf. Intell. Comput. Control Syst. ICICCS 2018 2019;67-71.

19. Gupta A, Jain R, Joshi R, Saxena R. Real time remote solar monitoring system. Proc. - 2017 3rd Int. Conf. Adv. Comput. Commun. Autom. (Fall), ICACCA 2017 2018;2018-Janua:1-5.

20. Shrihariprasath B, Rathinasabapathy V. A smart IoT system for monitoring solar PV power conditioning unit. IEEE WCTFTR 2016 - Proc. 2016 World Conf. Futur. Trends Res. Innov. Soc. Welf. 2016;

21. Oukennou A, Berrar A, Belbhar I. Low Cost IoT System for Solar Panel Power Monitoring To cite this version: HAL Id: hal-02298769 Low Cost IoT System for Solar Panel Power Monitoring. Proc. 2019 Int. Conf. Innov. Information, Embed. Commun. Syst. ICIIECS 2019 2019;

22. Saravanan D, Lingeshwaran T. Monitoring of solar panel based on IOT. 2019 IEEE Int. Conf. Syst. Comput. Autom. Networking, ICSCAN 2019 2019;15.

23. Hegarty A, Westbrook G, Glynn D. A Low-cost remote solar energy monitoring system for a buoyed iot ocean observation platform. IEEE 5th World Forum Internet Things, WF-IoT 2019 - Conf. Proc. 2019;386-91.

24. Rouibah N, Barazane L, Mellit A. A low-cost monitoring system for maximum power point of a photovoltaic system using IoT technique. 2019 Int. Conf. Wirel. Technol. Embed. Intell. Syst. WITS 2019 2019;1-5.

25. Murdan AP, Caremben S. An autonomous solar powered wireless monitoring and surveillance system. Proc. 13th IEEE Conf. Ind. Electron. Appl. ICIEA 2018 2018;784-9. 